\section{Searches begin and end}

\section{Bruce Ponder}

Three papers ${ }^{1-3}$, to appear in the 30 September and 7 October issues of Science, report the identification of one gene that predisposes to breast cancer, and the first genetic mapping of another. These two genes, called $B R C A 1$ and $B R C A 2$, together probably account for about two-thirds of familial breast cancer, or roughly $5 \%$ of all cases. $B R C A l$ is also associated with predisposition to ovarian cancer.

The first evidence of linkage for a breastcancer predisposing gene was reported in 1990 (ref. 4). The locus, on chromosome $17 \mathrm{q}$, was designated $B R C A 1$. Analysis of more than 200 families by an international consortium has shown that $B R C A 1$ is probably responsible for about one-third of families with multiple cases of breast cancer only, but more than $80 \%$ of families in which there is both breast cancer and epithelial ovarian cancer $^{5}$. A woman who has inherited the $B R C A 1$ gene in an extensive family has a $60 \%$ risk of breast cancer by the age of 50 , and a $90 \%$ lifetime risk; the risk of ovarian cancer seems to be similarly high in some families but much less in others, suggesting allelic heterogeneity or even two closely linked genes ${ }^{6}$.

Linkage mapping by the consortium rapidly refined the chromosomal location of $B R C A 1$ to a 1-2 megabase-pair region of chromosome $17 \mathrm{q} 12-21$. For the past $2-3$ years, about eight groups worldwide have been engaged in a positional cloning race, which has finally been won by the Myriad Genetics Inc./University of Utah group led by Mark Skolnick ${ }^{1}$. Their gene consists of 21 exons, distributed over more than 100 kilobases of genomic DNA adjacent to the locus $D I 7 S 855$, encoding a protein of 1,863 amino acids. On northern blots, there is a single 7.8-kilobase transcript, which is expressed in several tissues, including breast and ovary. The amino-terminal region of the protein contains a $\mathrm{C} 3 \mathrm{HC} 4$ zinc-finger domain similar to those found in many DNAbinding proteins, whereas the rest of the protein, especially the carboxy terminus, contains an excess of acidic residues. These features suggest that the protein may be a transcription factor.

The evidence that this gene is $B R C A I$ is strong. It maps to the critical region. Sequence variants found in three of eight breast or breast/ovarian cancer kindreds comprise a stop codon, a frameshift and a missense resulting in substitution of methionine by arginine. None of these variations was seen in controls, and in each family the sequence variation segregated with the disease. In a fourth kindred, polymorphisms within the coding sequence suggest that a mutation results in the absence of the messenger RNA transcript from one $B R C A 1$ allele. This variant also segregates with the disease. There are too few mutations as yet to assess possible correlations with the pattern of cancers in the families.

How do the mutations affect the function of the gene? The three coding sequence mutations are consistent with loss-of-function or a dominant-negative effect. Straightforward loss of function seems likely for the fourth mutation, in which the transcript of one $B R C A 1$ allele is apparently absent. This is consistent with the idea that $B R C A 1$ is a tumour-suppressor gene, already mooted because of the consistent finding that allele losses in the BRCAI region in familial tumours affect the wild-type chromosome ${ }^{7,8}$, which is now open to confirmation by mutation analysis of the wild-type $B R C A I$ allele in familial tumours.

At this point the story takes an unexpected twist. Futreal et al. ${ }^{3}$ report a search for $B R C A 1$ mutations in 32 apparently sporadic breast and 12 ovarian cancers, about one-third of them diagnosed in patients below 45 years of age, and all selected for having allele loss affecting one chromosome in the $B R C A 1$ region. If $B R C A 1$ is involved in the genesis of sporadic as well as familial tumours, as has usually been the case with cancer-predisposing genes, a fair number of BRCAI mutations would have been expected. In fact, only four were found; and, strikingly, each of these was also present in germline DNA of the same patient. This implies that $B R C A 1$ mutations may be relatively unimportant in sporadic cancers. One explanation might be that other genes lying in the same or alternative pathways of tumorigenesis are a more frequent target of mutation in somatic tissues. Alternatively, mutations in BRCA1 may lead to tumour formation only if they are present at a specific stage early in breast or ovarian development. Meanwhile, the observations of frequent allele losses at or adjacent to the $B R C A I$ region in sporadic tumours ${ }^{9-12}$ suggest that there may be other tumoursuppressor genes in the region.

The second predisposing gene, $B R C A 2$, has been mapped by a group based on the International Breast Cancer Linkage Consortium, and led from the Institute of Cancer Research in Sutton, UK, and from $\mathrm{Utah}^{2}$. A genome-wide linkage search using microsatellite markers yielded strong evidence (LOD 11.65) for a predisposing gene lying within a 6-centimorgan (roughly 100-gene) interval on chromosome 13q12-13, centred on D13S260. Allele losses in sporadic tumours suggest that $B R C A 2$ may also be a suppressor gene: but interpretation is complicated by the closeness of another known suppressor $R B I$ (ref. 13), which is, however, excluded as a $B R C A 2$ candidate by recombination. $B R C A 2$ now stands where $B R C A 1$ stood in 1990 . If known candidate genes, such as the putative tumour-suppressor Brush-1 (ref. 14), are excluded, another positional cloning race is in prospect.

$B R C A 1$ and $B R C A 2$ are probably of roughly equal importance in conferring risk of early-onset female breast cancer. However, no male breast cancers have been seen in $B R C A 1$ families $^{15}$, whereas several cases are present in the $B R C A 2$ family set; and ovarian cancer is prominent in some $B R C A 1$ families ${ }^{6}$, but apparently much less so in $B R C A 2$. At present, these differences are unexplained. Heterogeneity analysis and lack of haplotype sharing by affected individuals in some multiple-case families suggest that there are other high-risk genes.

In the short term, the practical implications of the $B R C A I$ cloning are for genetic testing. Until now $B R C A 1$ testing using linked markers has necessarily been limited to the rather few families in which cancer could be clearly shown to be due to $B R C A 1$. Even in these high-risk families, many issues are unresolved ${ }^{16}$. In particular, it is not clear what can be offered to a woman who tests positive in terms of effective screening or prevention. Experience with other adultonset inherited disorders has shown that even a negative DNA test may not provide the expected reassurance. With the cloning of $B R C A 1$, and the possibility of direct mutation testing, these uncertainties are suddenly extended to the much larger numbers of women who have only one or two af fected relatives, and even perhaps to screening for $B R C A 1$ mutations in the population as a whole.

There are practical issues: the gene is large, and it is not yet clear how widely the mutations are scattered, and how easy or costly large-scale testing will be. It is possible that there will be a spectrum of $B R C A 1$ mutations associated with greater or lesser risk. Further work is needed to develop methods of early diagnosis and prevention, and to determine the best ways of informing the public and doctors. It is premature to offer population screening until these issues are resolved: but if people are to be denied access to screening, they will need to understand why.

Bruce Ponder is in the Cancer Research Campaign Human Cancer Genetics Group, Department of Pathology, University of Cambridge, Cambridge, UK.

\footnotetext{
1. Miki, Y. et al. Science (in the press).

2. Wooster, R. et al. Science (in the press)

3. Futreal, P. A. et al. Science (in the press)

4. Hall, J. M. et al. Science 250, 1684-1689 (1990).

5. Easton, D.F. et al. Am. J. hum. Genet. 52. 678-701 (1993).

6. Ford, D. et al. Lancet 343, 692-695 (1994)

7. Smith, S. A. et al. Nature Genet. 2, 128-131 (1992)

8. Kelsell, D. P., Black, D. M., Bishop, D. T. \& Spurr, N. K. Hum molec. Genet. 2, 1823-1828 (1993).

9. Jacobs, I. J. et al. Cancer Res. 53, 1218-1221 (1993). 10. Nagai, M. et al. Genes Chrom. Cancer 11, 58-62 (1994) 11. Saito, H. et al. Cancer Res. 53, 3382-3385 (1993).

12. Cropp, C. S. et al. Cancer Res. 54, 2548-2551 (1994)

13. Devilee, P. et al. Genomics 5, 554-560 (1989).

14. Schott, D. R. et al. Cancer Res. 54, 1393-1396 (1994).

15. Stratton, M. R. et al. Nature Genet. 7, 103-107 (1994)

16. King, M.C., Rowell, S. \& Love, S. M. J. Am. med. Ass. 269
} $1975-1980$ (1993). 